Open Access

\title{
Dasatinib blocks transcriptional and promigratory responses to transforming growth factor-beta in pancreatic adenocarcinoma cells through inhibition of Smad signalling: implications for in vivo mode of action
}

Tobias Bartscht ${ }^{1 \dagger}$, Benjamin Rosien ${ }^{1 \dagger}$, Dirk Rades$^{2}$, Roland Kaufmann ${ }^{3}$, Harald Biersack ${ }^{1}$, Hendrik Lehnert ${ }^{1}$, Frank Gieseler ${ }^{1}$ and Hendrik Ungefroren ${ }^{1 *}$

\begin{abstract}
Background: We have previously shown in pancreatic ductal adenocarcinoma (PDAC) cells that the SRC inhibitors PP2 and PP1 effectively inhibited TGF- $\beta 1$-mediated cellular responses by blocking the kinase function of the TGF- $\beta$ type I receptor ALK5 rather than SRC. Here, we investigated the ability of the clinically utilised $S R C / A B L$ inhibitor dasatinib to mimic the PP2/PP1 effect.
\end{abstract}

Methods: The effect of dasatinib on TGF- $\beta 1$-dependent Smad2/3 phosphorylation, general transcriptional activity, gene expression, cell motility, and the generation of tumour stem cells was measured in Panc-1 and Colo-357 cells using immunoblotting, reporter gene assays, RT-PCR, impedance-based real-time measurement of cell migration, and colony formation assays, respectively.

Results: In both PDAC cell lines, dasatinib effectively blocked TGF- $\beta 1$-induced Smad phosphorylation, activity of 3TPlux and pCAGA ${ }_{(12)}-$ luc reporter genes, cell migration, and expression of individual TGF- $\beta 1$ target genes associated with epithelial-mesenchymal transition and invasion. Moreover, dasatinib strongly interfered with the TGF- $\beta 1$-induced generation of tumour stem cells as demonstrated by gene expression analysis and single cell colony formation. Dasatinib also inhibited the high constitutive migratory activity conferred on Panc-1 cells by ectopic expression of kinase-active ALK5.

Conclusions: Our data suggest that the clinical efficiency of dasatinib may in part be due to cross-inhibition of tumour-promoting TGF- $\beta$ signalling. Dasatinib may be useful as a dual TGF- $\beta / S R C$ inhibitor in experimental and clinical therapeutics to prevent metastatic spread in late-stage PDAC and other tumours.

Keywords: Dasatinib, TGF- $\beta$, Smad, PDAC, Cell migration, Invasion, Activin receptor-like kinase 5

\footnotetext{
* Correspondence: hendrik.ungefroren@uksh.de

${ }^{\dagger}$ Equal contributors

${ }^{1}$ First Department of Medicine, UKSH, Campus Lübeck, 23538 Lübeck,

Germany

Full list of author information is available at the end of the article
}

(c) 2015 Bartscht et al. Open Access This article is distributed under the terms of the Creative Commons Attribution 4.0 International License (http://creativecommons.org/licenses/by/4.0/), which permits unrestricted use, distribution, and reproduction in any medium, provided you give appropriate credit to the original author(s) and the source, provide a link to the Creative Commons license, and indicate if changes were made. The Creative Commons Public Domain Dedication waiver (http://creativecommons.org/publicdomain/zero/1.0/) applies to the data made available in this article, unless otherwise stated. 


\section{Background}

Despite significant progress in the biology of pancreatic ductal adenocarcinoma (PDAC), treatment options for affected patients are still very limited and far from being curative with the exception of surgery (R0 resection). Chemotherapy is complicated by the desmoplastic nature of the complex mircoenvironmental architecture of the tumour tissue which is known to favour metastasis and chemoresistance of tumour cells.

Due to its overexpression in PDAC and its various functions in driving tumour suppression, the non-receptor tyrosine kinase SRC represents a promising biological target in experimental and clinical approaches to treat PDAC [1-3]. Dasatinib (N-(2-chloro-6-methyl- phenyl)2-(6-(4-(2-hydroxyethyl)- piperazin-1-yl)-2-methylpyrimidin-4- ylamino)thiazole-5-carboxamide; BMS-354825, Sprycel), a tyrosine kinase inhibitor originally developed against BCR-ABL and SRC [4] and currently used in the treatment of CML [5] and Philadelphia chromosomepositive acute lymphoblastic leukemia (reviewed in [6]), has also shown promise in the treatment of various epithelial tumours [6] including pancreatic cancer. Dasatinibmediated inhibition of SRC slowed tumour progression and metastasis of human PDAC cells in an orthotopic mouse model [7], and stimulated migration, invasion, and apoptosis in human [8] and murine [9] PDAC cells. Moreover, dasatinib inhibited metastasis in a mouse model of PDAC but failed to suppress primary tumour growth and prolong survival [7]. Along the same lines, a phase II study found that dasatinib as a single-agent did not have clinical activity as first-line therapy in patients with metastatic PDAC [10].

Several preclinical studies have shown that dasatinib can potentiate the antitumoural action of various other anticancer drugs (reviewed in [11]. For instance, dasatinib synergized with gemcitabine to induce anti-proliferation and apoptosis in the pancreatic cancer cell line MIA $\mathrm{PaCa}-2$ by decreasing the levels of ALDH1A1, a marker of tumour-initiating/cancer stem cells [12]. Interestingly, 2/8 patients with pancreatic cancer (both gemcitabine-refractory) who received both gemcitabine and dasatinib showed a partial response (stable disease $\geq 6$ months) [13]. When dasatinib was combined with gemcitabine and erlotinib (an epidermal growth factor-receptor (EGF-R) inhibitor), it inhibited the growth of xenografts of both sensitive and resistant PDAC cells in vivo without increasing toxicity [14]. More recently, concomitant targeting of SRC, EGF-R, and transforming growth factor (TGF)- $\beta$ has been suggested as a novel therapeutic approach in pancreatic cancer [15].

Although originally developed as an inhibitor of BCR-ABL and SRC [16], dasatinib, in drug affinity chromatography experiments was shown to interact with over 40 kinases, including SRC family kinases (SFKs), receptor tyrosine kinases, serine/threonine kinases (STK), MAP kinases, and EphA2 [17]. One of the STKs identified with this approach was the type I receptor for TGF- $\beta$ (T $\beta R I$, also termed activin receptor-like kinase 5, ALK5) [18]. TGF- $\beta 1$ is a pleiotropic growth factor that controls several aspects of tumour cell behavior such as proliferation, angiogenesis, desmoplasia, cell migration/invasion, and metastasis. It has a central role in the initiation and progression of PDAC [19] which is evident from the observation that its aberrant expression in advanced tumour stages is associated with decreased survival in PDAC patients [20], and that the TGF- $\beta 1$ signalling pathway is among the 12 core pathways that are genetically altered in $100 \%$ of PDAC tumours [21]. Besides ALK5, TGF- $\beta 1$ requires a second membrane-bound STK receptor, designated type II (TRRII), for signal transmission into cells. Upon phosphorylation by T $\beta R I I$, ALK5 initiates canonical Smad as well as non-Smad signalling pathways [22] that together mediate the promigratory and proinvasive effects of TGF- $\beta$. For PDAC, this is evident from the Panc-1 orthotopic mouse model in which ectopic expression of kinase-active ALK5 (ALK5 ${ }^{\mathrm{T} 204 \mathrm{D}}$ ) strongly enhanced metastasis [23] while pharmacologic inhibition of endogenous ALK5 suppressed it [24]. Targeting ALK5 in vivo is therefore a feasible approach to the treatment of PDAC and other carcinomas.

Like SRC, TGF- $\beta$ /ALK5 signalling is currently targeted in the experimental and clinical treatment of various tumours. Given i) the interaction of dasatinib with ALK5 $[18,25]$, ii) the structural similarity of dasatinib with the experimental SRC inhibitors PP2 and PP1, and iii) the ability of PP2 and PP1 to effectively inhibit the ALK5 kinase activity as well as TGF- $\beta 1$-induced prooncogenic responses [26, 27], we hypothesized that dasatinib should be able to block TGF- $\beta 1$ signalling towards migratory, invasive and prometastatic outcomes. That dasatinib may possess potential efficacy against profibrotic TGF- $\beta$ signalling in vivo was suggested by preclinical studies, in which dasatinib treatment of scleroderma and normal fibroblasts led to decreased production of extracellular matrix proteins [28]. In light of the clinical use and efficacy of dasatinib, it is mandatory to understand its molecular mode of action in vivo including possible side-effects, regardless of whether they are adverse or beneficial for the patients.

To investigate the effect of dasatinib on TGF- $\beta /$ ALK5 signalling in PDAC, we employed two TGF- $\beta$ sensitive cell lines (Panc-1, Colo-357) that have been used in orthotopic mouse models of PDAC for evaluation of TGF- $\beta$ antitumour activity in vivo [23, 29]. Using impedance-based real-time measurement of cell migration, we show here that dasatinib strongly and dose-dependently inhibited TGF- $\beta 1$-induced migratory responses in vitro. As a result of dasatinib inhibition, activation of $\operatorname{Smad} 2 / 3$, upregulation 
of TGF- $\beta$ transcriptional reporter genes as well as EMT/ migration/invasion-associated gene expression in PDACderived cell lines was compromised. These results have implications for the use of dasatinib in experimental therapeutics, providing a molecular explanation for the reduction in the cells' migratory response and an in vivo correlate for its anti-metastatic action. Furthermore, our data suggest that this agent based on its dual effect on protumourigenic TGF- $\beta$ and SRC signalling pathways may be useful in the treatment of late stage metastatic disease in PDAC.

\section{Results \\ Dasatinib blocks TGF- $\beta 1$-induced Smad2/3 activation in PDAC cells}

In order to test whether dasatinib can inhibit ALK5 function, we measured its effect on TGF- $\beta 1$-induced C-terminal phosphorylation of Smad2 and Smad3 (p-Smad2C/3C), reflecting their state of activation. To this end, dasatinib dose-dependently inhibited TGF- $\beta 1$ induced $\mathrm{p}-\mathrm{Smad} 2 \mathrm{C}$ and $\mathrm{p}-\mathrm{Smad} 3 \mathrm{C}$ in both Panc-1 and Colo-357 cells with the greatest effects seen at concentrations $>0.1 \mu \mathrm{M}$ (Fig. 1). A comparison of signal strengths between Panc-1 and Colo-357 cells after quantification by densitometry revealed that the dasatinib effect on both p-Smads was more pronounced in Panc-1 cells (Fig. 1).

\section{Dasatinib blocks TGF- $\beta 1$-induced reporter gene activity}

The above data showed that TGF- $\beta 1$-induced Smad2 and Smad3 activation was sensitive to dasatinib inhibition. Hence, we wondered whether this effect of dasatinib on the central mediators of TGF- $\beta$ signalling would have consequences for Smad-mediated transcriptional activation of TGF- $\beta 1$ target genes. To this end, cells were transiently transfected with the TGF- $\beta$ reporter genes $\mathrm{pCAGA}_{(12)}$-luc or 3TPlux. While $\mathrm{pCAGA}_{(12)}$-luc is Smad-specific and responds to binding of $\mathrm{Smad} 3 / 4 \mathrm{ra}-$ ther than Smad2/4 to the Smad binding elements (SBEs) in this plasmid [30], the 3TPlux plasmid contains promoter sequences from the plasminogen activatorinhibitor-1 gene and is responsive to both Smad and non-Smad pathways [31]. Treatment of Panc-1 cells with a combination of TGF- $\beta 1$ and dasatinib strongly suppressed the response of both pCAGA $(12)$-luc and 3TPlux to TGF- $\beta 1$ induction in a dose-dependent manner (Fig. 2), and at a concentration of $10 \mu \mathrm{M}$ was equally effective in suppressing reporter gene activity as the established ALK5 inhibitor SB431542 at $5 \mu \mathrm{M}$ (Fig. 2). In contrast, the SRC inhibitor bosutinib (SKI-606, $\mathrm{IC}_{50}=1.2 \mathrm{nM}$ ) was unable to interfere with TGF- $\beta$ transcriptional activity. Thus, dasatinib appears to be a powerful inhibitor of transcriptional responses to TGF- $\beta$ in PDAC-derived cell lines.
Dasatinib blocks TGF- $\beta 1$-induced expression of genes associated with EMT, migration/invasion and stemness Next, we asked whether dasatinib would also affect TGF- $\beta 1$-induced upregulation of genes involved in EMT, cell migration, and invasion. Dasatinib at $10 \mu \mathrm{M}$ effectively prevented the TGF- $\beta 1$-induced downregulation of E-cadherin in Panc-1 cells and dramatically inhibited TGF- $\beta 1$ induction of $\mathrm{N}$-cadherin, vimentin, MMP2, MMP9, Slug and Snail in Colo-357 and Panc-1 cells as demonstrated by quantitative RT-PCR (qPCR, Fig. 3a) and immunoblotting (Fig. 3b). Although TGF- $\beta$ induction of Snail protein in Colo-357 cells and N-cadherin protein in Panc-1 cells was only moderate, levels were clearly reduced upon dasatinib treatment (Fig. 3b). To show that the dasatinib-induced changes were caused by inhibition of ALK5 rather than SRC, we treated Colo357 and Panc-1 cells, as above in the reporter gene assays (Fig. 2), with either SB431542 or bosutinib and repeated the GPCR analysis for two central regulators of TGF- $\beta$-induced EMT, Slug and vimentin (Fig. 3c). While SB431542 effectively abolished the TGF- $\beta$ effect on Slug and vimentin mRNA levels in both cell lines, bosutinib lacked statistically significant effects (Fig. 3c).

Since this gene expression profile suggested that dasatinib might be able to interfere with TGF- $\beta 1$-induced EMT and partial EMT has been shown to be associated with the aquisition of stem cell traits [32], we subjected Panc-1 cells to a long-term treatment with TGF- $\beta 1$ according to a previously published protocol [32] to study the effect of dasatinib on the induction of stem cell gene expression. To this end, a 14-day exposure to TGF- $\beta 1$ resulted in the upregulation of several pluripotencyassociated genes: The TGF- $\beta$ ligand superfamily members $\beta_{\mathrm{A}}$ activin and BMP2, the membrane-associated markers CD90, CD105 (also termed endoglin, a TGF- $\beta$ coreceptor), and the transcriptional regulators OCT4 (the stem cell associated OCT4A isoform) and UTF1 (Fig. 4). Moreover, we observed downregulation of the adhesion molecule NCAM1 (Fig. 4a) and, surprisingly, of the xenobiotic transporter ATP-binding cassette subfamily G member 2 (ABCG2) (Fig. 4). Intriguingly, the TGF- $\beta 1$ effect on all genes tested was effectively inhibited by concomitant treatment with dasatinib (Fig. 4a). To verify the possibility that dasatinib is able to block the TGF- $\beta / E M T-i n d u c e d$ generation of cells with stem cell character, we repeated the 14-day treatment of Panc-1 cells with TGF- $\beta 1$ in the absence or presence of dasatinib, or SB431542 as control (long-term treatment of these cells with bosutinib was not possible due to its toxicity). Subsequently, we employed the colony formation assay (CFA) to assess the number of cells with stem cell features by virtue of their ability to generate from a single cell a microscopically discernible clone or colony [33, 34]. A quantitative analysis by counting revealed that both 


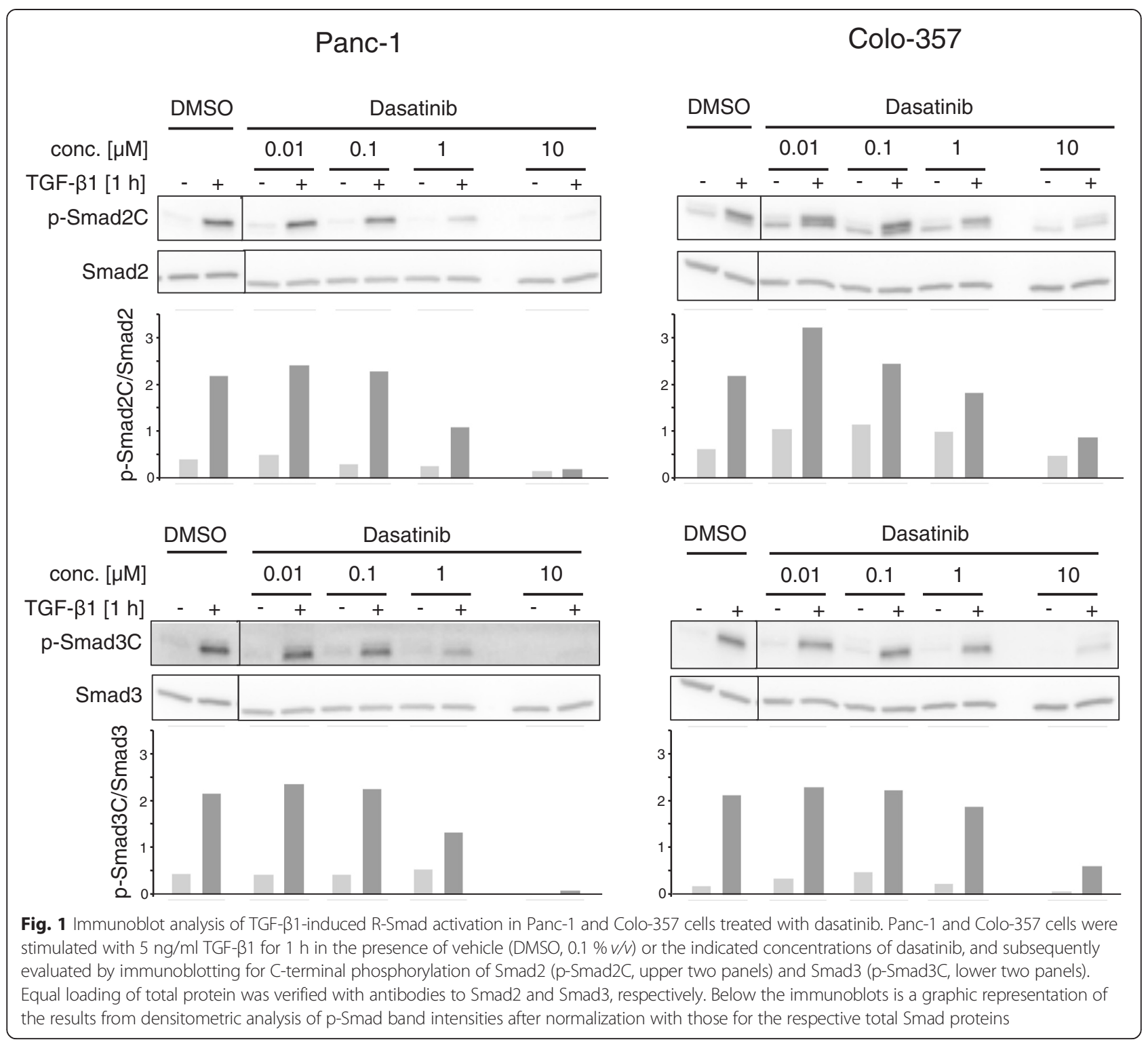

dasatinib, and SB431542 as control, strongly decreased the number of colonies/clones that arose from TGF- $\beta 1$ treated cultures relative to untreated controls (Fig. 4b). Together, our data suggest that dasatinib interferes with TGF- $\beta$-induced EMT and stem cell generation and raise the possibility that it can block the generation of tumourinitiating cells in vivo.

\section{Dasatinib blocks TGF- $\beta 1$-induced cell migration}

Given the ability of dasatinib to block TGF- $\beta 1$-induced EMT and cell motility-associated gene expression as well as Smad activation and transcriptional activity in conjunction with the requirement for Smad3 for TGF- $\beta 1$ dependent migration of PDAC cells [35], we hypothesized that dasatinib also interferes with TGF- $\beta 1$-induced cell motility in PDAC cells. To this end, dasatinib at the
$10 \mu \mathrm{M}$ concentration abolished both basal and TGF- $\beta 1$ stimulated cell migration in both Panc-1 and Colo-357 cells (Fig. 5a). To determine whether this antimigratory effect of dasatinib was dose-dependent and to be able to calculate the concentration of half-maximal inhibition, we serially diluted the dasatinib and repeated the migration assays with lower concentrations. Interestingly, a concentration as low as $0.01 \mu \mathrm{M}$ afforded an approximately $50 \%$ reduction in migration activity in both cell types (Fig. $5 \mathrm{~b}$, magenta curves). With respect to inhibition of TGF- $\beta 1$ stimulated migration, the dasatinib effect was comparable to that of SB431542 affording complete inhibition (Fig. 5c), however, dasatinib unlike SB431542 also suppressed the increase in basal migratory activity which in contrast to Colo-357 cells was quite high in Panc-1 cells (Fig. 5c). Interestingly, we have shown earlier that the high basal 


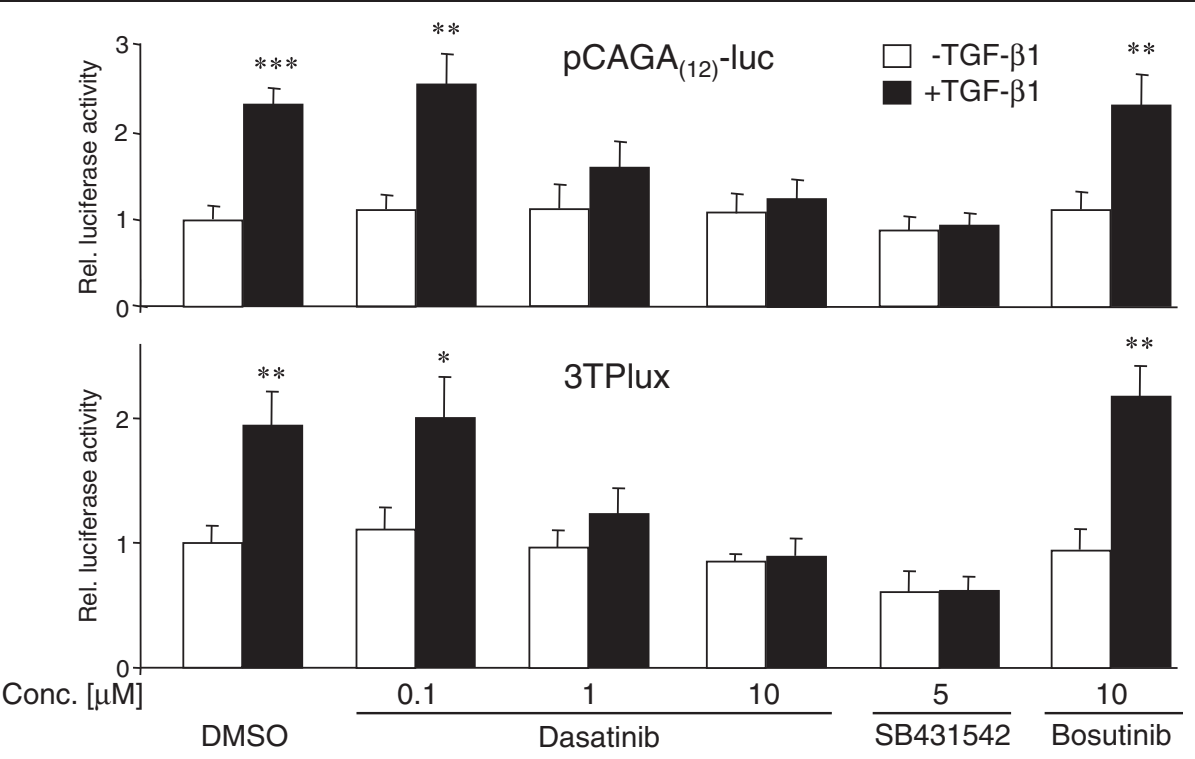

Fig. 2 Treatment of Panc-1 cells with dasatinib decreases the sensitivity of TGF- $\beta / S$ mad-responsive reporters to TGF- $\beta 1$ stimulation. Panc-1 cells were transfected on day 1 with either pCAGA ${ }_{(12)}$-luc (upper graph) or 3TPlux (lower graph), and the Renilla luciferase-encoding vector pRL-TK-luc using LipofectAmine 2000. Twenty-four $h$ after the start of transfection, cells were stimulated with TGF- $\beta 1$ for another 24-h period in the presence of $0.1 \%$ DMSO or the indicated concentrations of dasatinib, SB431542, or bosutinib, followed by dual luciferase measurements. Data represent firefly luciferase values normalised with those for Renilla luciferase (displayed as relative (rel.) luciferase activities with those for DMSO/non-TGF- $\beta 1$ treated cells set arbitrarily at 1) and are the mean \pm SD from three independent assays. Asterisks indicate significance of TGF- $\beta 1$-treated cells vs. the respective untreated control $(n=3)$

migration (which precedes TGF- $\beta 1$-stimulated migration) was SRC-dependent [36], suggesting that in Panc-1 cells dasatinib acts as a dual inhibitor of ALK5 and SRCmediated migration. Together, these results clearly show that dasatinib, in a very sensitive and effective fashion, blocked TGF- $\beta 1$-induced migration/invasion in PDAC cells in vitro. This data together with those presented in Figs. 1, 2, and 3 strongly support our contention that dasatinib represents a powerful inhibitor of TGF- $\beta 1$-induced cell motility by inhibiting ALK5 rather than SRC or other SFKs.

\section{Dasatinib inhibits the high constitutive migratory activity of Panc-1 Cells expressing kinase-active ALK5}

As shown previously, the experimental SRC inhibitors PP2 and PP1 strongly interfered with the high constitutive migratory activity conferred on these cells by ectopic expression of $\mathrm{ALK} 5^{\mathrm{T} 204 \mathrm{D}}$, a kinase-active version of ALK5 that harbors an activating point mutation in its glycine- and serine-rich (GS) domain [37] and does not rely on ligand binding, complex formation and phosphorylation by the T $\beta$ RII kinase in order to signal. To test whether dasatinib was capable of mimicking the PP1/PP2 effect, we subjected Panc-1-ALK5 ${ }^{\text {T204D }}$ cells (one of several individual and previously characterised clones [23]) to the RTCA migration assay. Notably, both dasatinib (Fig. 6a) and SB431542 (Fig. 6b) strongly reduced both migration directed by the exogenously expressed ALK5 ${ }^{\mathrm{T} 204 \mathrm{D}}$ receptors and the extra portion induced by stimulation of endogenous (non-mutant) receptors in response to their activation by recombinant TGF- $\beta 1$ ligand. These data are consistent with the results from dasatinib inhibition of ligand-induced cell migration in wild-type cells (see Fig. 5) and confirm that dasatinib targets the ALK5 kinase function or events downstream thereof for inhibition.

\section{Discussion}

The tyrosine kinase inhibitor dasatinib at low concentrations (IC $<1.0 \mathrm{nM}$ ) potently inhibits ABL and SFKs. At higher concentrations it also inhibits other TKs and STKs such as ALK5, p38 MAPK, AKT, and FAK, all of which have been implicated in TGF- $\beta$ signalling either in the canonical branch (ALK5), as downstream mediators of Smads (AKT, FAK, p38 MAPK) or in the noncanonical branch (p38 MAPK, FAK) [22]. ALK5 was originally identified by drug affinity chromatography to interact directly with dasatinib [18]. Later, this observation was confirmed in docking studies using the previously reported crystal structure of the ALK5 cytoplasmic domain. Here, the binding of dasatinib to ALK5 presented with the highest score when compared to the structurally related bosutinib, the commercially available ALK5 inhibitor LY-364947, and dorsomorphin [25].

Likewise, we have shown previously that PP2 and PP1, which share structural similarity with dasatinib, effectively 


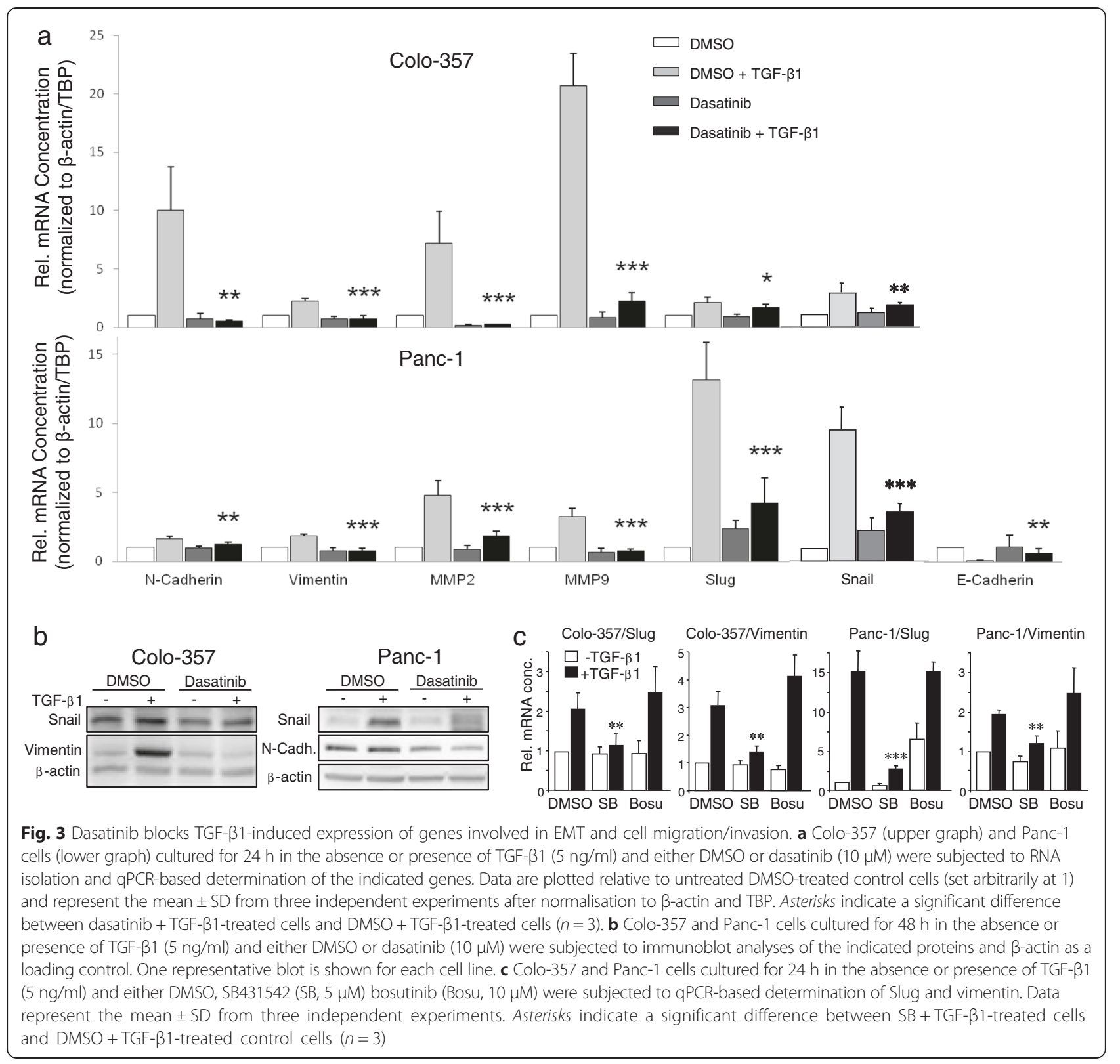

attenuated various oncogenic responses to TGF- $\beta 1$ in malignant PDAC cell lines and strongly inhibited ALK5 kinase activity in in vitro kinase assays [26]. In the present study, we have tested in the Panc-1 and Colo-357 cell lines the prediction that dasatinib can mimic the action of PP2 and PP1 on TGF- $\beta$ signalling. We found that dasatinib effectively blocked TGF- $\beta 1$-dependent reporter gene activity, Smad2/3 activation and cell migration. The inhibitory effect of dasatinib $\left(\mathrm{IC}_{50}=0.8 \mathrm{nM}\right.$ for $\mathrm{SRC}$ in cell-free assays) on ligand-induced reporter gene activity was not dependent on SRC since it was not mimicked by another SRC inhibitor, bosutinib $\left(\mathrm{IC}_{50}=1.2 \mathrm{nM}\right.$, [38]). Moreover, dasatinib strongly inhibited migration driven by the ALK5 $5^{\text {T204D }}$ mutant (Fig. 6). The inhibitory effect of dasatinib on TGF- $\beta 1 /$ ALK5-mediated cell motility corresponded well with the potency of this agent to inhibit various TGF- $\beta 1$-regulated marker genes involved in EMT, migration/invasion, and a cancer stem cell phenotype. Consistent with this, qPCR assays revealed that dasatinib suppressed TGF- $\beta 1$ induction of MMP2, MMP9, Ncadherin, vimentin, Snail and Slug in Panc-1 and Colo-357 cells. In Panc-1 cells, dasatinib also attenuated downregulation of the adhesion molecules E-cadherin and NCAM1, together providing a molecular explanation for the anti-migratory/anti-invasive effect of dasatinib. Moreover, dasatinib effectively prevented the TGF- $\beta 1$ - 


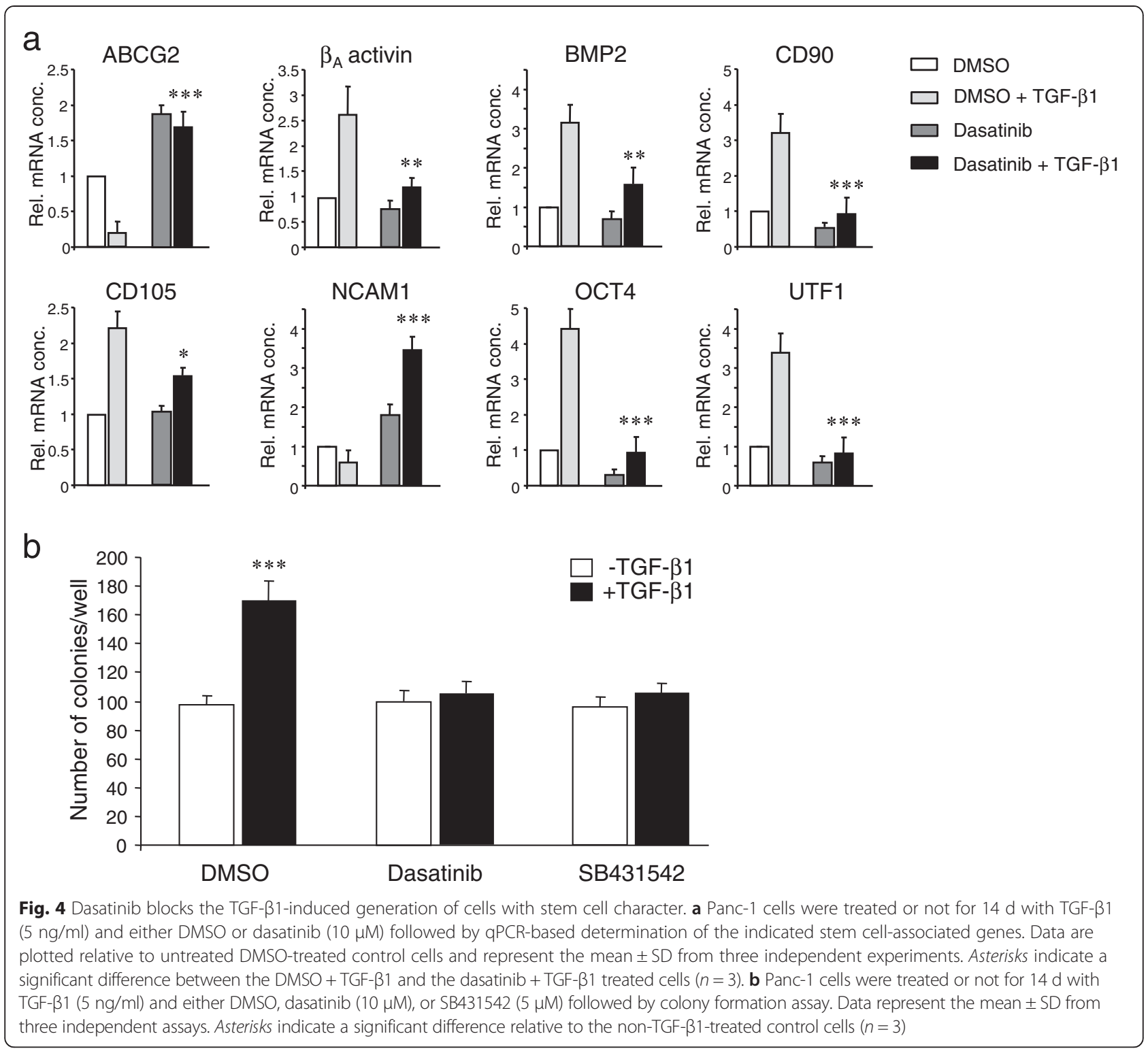

induced upregulation of several stem cell-associated genes, some of which are either members of the TGF- $\beta$ superfamily of ligands ( $\beta_{\mathrm{A}}$ activin, BMP2) or function as a co-receptor for TGF- $\beta$ (CD105/endoglin) and strongly decreased the number of colonyforming units derived from long-term TGF- $\beta 1$-treated cells assumed to derive from cancer stem cells. From these data, we conclude that dasatinib targets ALK5 for inhibition of TGF- $\beta$-induced cell motility in vitro and likely also other EMT-associated changes such as cancer stem cell differentiation.

Gordian and colleagues [25] studied the combined effects of dasatinib and TGF- $\beta$ on A549 NSCLC cells. When combined with TGF- $\beta 1$ stimulation, dasatinib induced apoptosis in EGF-R mutant cells along with upregulation of pro-apoptotic BIM protein. Unfortunately, cell motility responses were not analysed in this study. For analysis of Smad2 and Smad3 activation by TGF- $\beta 1$, these authors used a single concentration of $100 \mathrm{nM}$ dasatinib rather than providing a dose-response curve with higher concentrations. With this dose they observed an increase in the levels of $\mathrm{p}-\mathrm{Smad} 3 \mathrm{C}$ compared to levels seen with TGF- $\beta 1$ alone. Interestingly, we also observed in PDAC cells a tendency for an increase or at least a lack of effect in the concentration range of 10-100 nM, which was particularly evident in the Colo-357 cell line (see Fig. 1).

Several drugs have been developed for blocking TGF- $\beta$ signalling that are in various stages of experimental and clinical evaluation. Strategies for inhibition of TGF- $\beta$ 

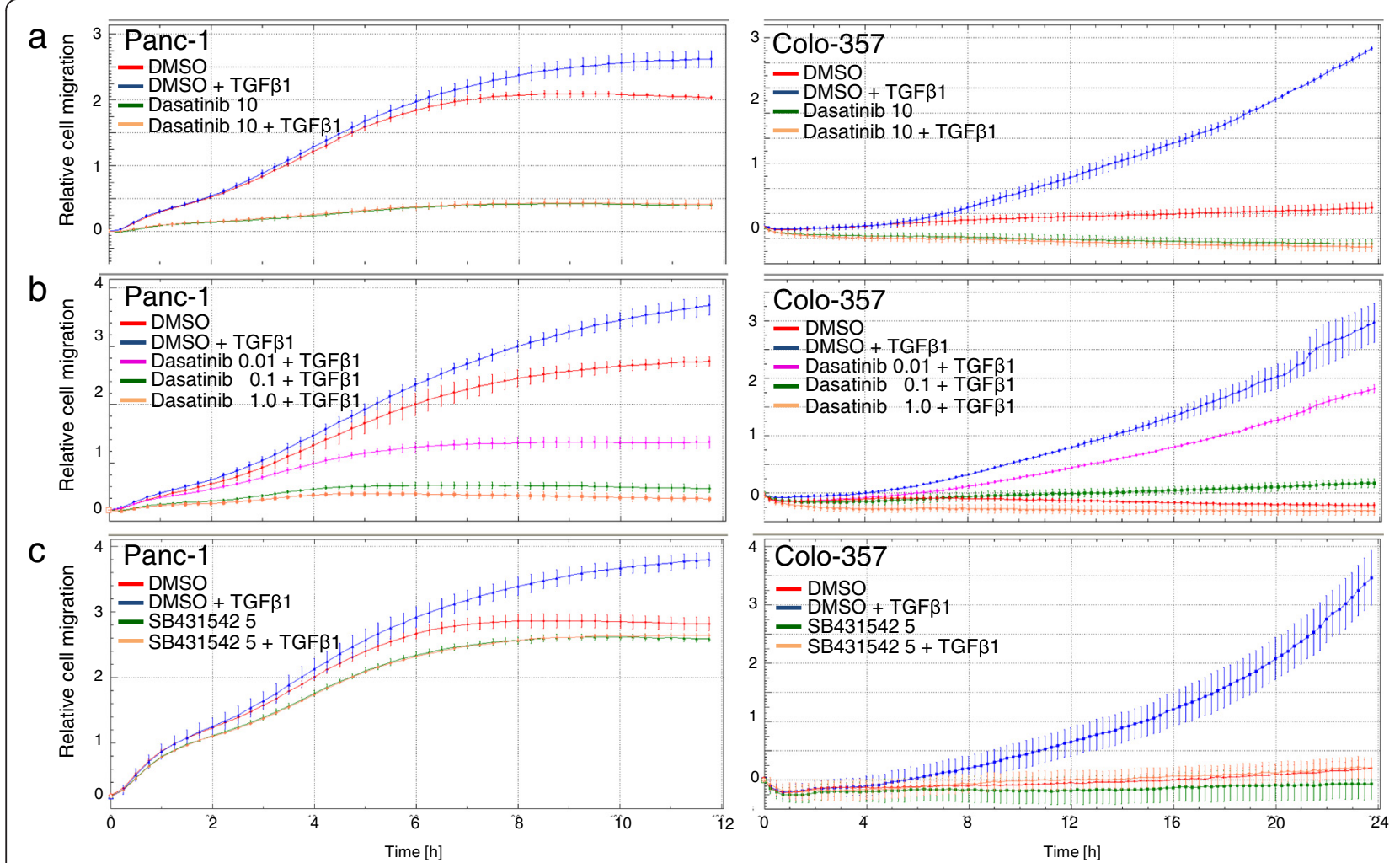

Fig. 5 Effect of dasatinib on TGF- $\beta 1$-induced cell migration in PDAC cell lines. Overnight starved Panc-1 or Colo-357 cells were resuspended in growth medium with $1 \%$ FCS and seeded into the wells of a CIM-Plate $16(60,000 /$ well) of the RTCA DP instrument. Cells were allowed to migrate in the presence of TGF- $\beta 1$ ( $5 \mathrm{ng} / \mathrm{ml}$, added to both the lower and upper compartment of each well) and either vehicle or dasatinib at the indicated concentrations ( $\mathbf{a} \&$ b) or SB431542 (c) as indicated by the colour code. Changes in impedance resulting from cells that have migrated to the bottom side of the membranes were recorded every $15 \mathrm{~min}$ and monitored for a total of $12 \mathrm{~h}$ (Panc-1) and $24 \mathrm{~h}$ (Colo-357). Data are from one representative experiment out of three experiments performed in total and are presented as means \pm SD of quadruplicate wells. In each graph, significance was calculated for vehicle + TGF- $\beta 1$ vs. dasatinib + TGF- $\beta 1$ (a \& b) or vs. SB431542 + TGF- $\beta 1$ (c). The first time point at which differences become significant are for Panc-1 cells: $10 \mu \mathrm{M}:$ 0:30 (a, left-hand graph); $1 \mu \mathrm{M}:$ 0:15; 0.1 $\mu \mathrm{M}: 0: 15 ; 0.01 \mu \mathrm{M}: 0: 30$ (b, left-hand

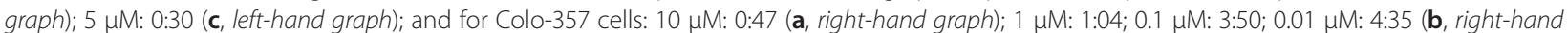
graph); $5 \mu \mathrm{M}$ : 0:30 (c, right-hand graph)

signalling include blocking i) the binding of TGF- $\beta$ to its receptors, ii) the ALK5 kinase using small molecules that act as competitive inhibitors for its ATP-binding site (SB431542, SB505124, SD-093, SD-208, LY580276, and Y2109761, a novel T $\beta R I$ and T $\beta$ RII dual inhibitor), and iii) Smad intracellular signal transduction via the Smad3 inhibitor SIS3 [39]. However, although many of these drugs show promise in pre-clinical studies, the dual role of TGF- $\beta$ in tumour progression requires a deeper understanding of the TGF- $\beta$ signalling crosstalk with other pathways in order to design successful therapeutic approaches and protect the patients from undesired side effects.

Taken together, our results clearly show that dasatinib can block the TGF- $\beta 1$-dependent cell motility at concentrations as low as $0.01 \mu \mathrm{M}$. However, this extremely sensitive and potent effect of dasatinib, particularly in Panc-1 cells (see Fig. 5), may have resulted from combined inhibition of ALK5 and SRC since we have previously shown that SRC contributed to TGF- $\beta 1$ mediated cell migration without affecting TGF- $\beta 1 /$ ALK5-induced activation of Smad2 and Smad3. This differential contribution of SRC may explain why dasatinib was able to block cell migration at much lower concentrations than phosphorylation of Smad2C/3C (compare Figs. 1 and 5). The higher efficacy of dasatinib in blocking TGF- $\beta 1$-induced cell motility may be due to coinhibition of p38 MAPK, the activation by TGF- $\beta 1$ of which is SRC-dependent [40] and required for cell migration in Panc-1 cells (H.U., unpublished observation). Experiments are currently underway to solve this issue. That dasatinib likely acted on SRC in the migration assays was evident from its suppressing effect on basal migration activity in Panc-1 cells which was previously shown to be SRC-dependent [36]. Notably, TGF- $\beta$ stimulation of p38 MAPK activation and cell invasion requires 


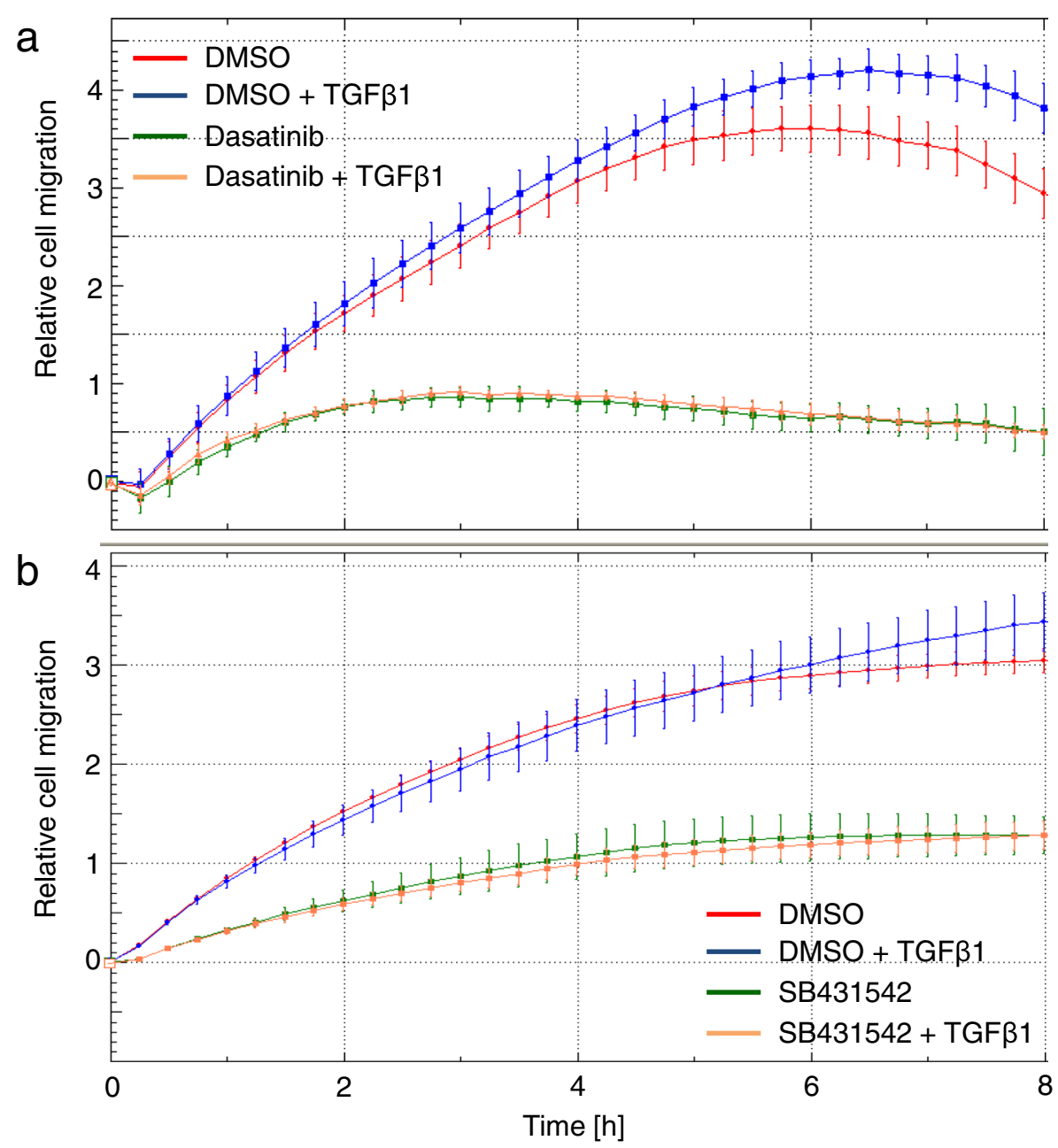

Fig. 6 Dasatinib inhibits cell migration induced by kinase-active ALK5. Cells (60,000/well) from a previously characterised clone of Panc-1-ALK5 ${ }^{\text {T204D }}$ cells were seeded into a CIM-Plate 16 for measurement of cell migration. Cells were allowed to migrate in the absence or presence of exogenous TGF- $31(5 \mathrm{ng} / \mathrm{ml})$ and either DMSO $(0.1 \%)$ or dasatinib $(10 \mu \mathrm{M})(\mathbf{a})$ or SB431542 $(5 \mu \mathrm{M})(\mathbf{b})$. Data shown are given as mean \pm SD of quadruplicate wells and were derived from one representative experiment out of three experiments performed in total. Significant differences in the cell index values between vehicle treated (red curve) and dasatinib-treated (green curve) Panc-1-ALK5 ${ }^{\text {TD }}$ cells, and between vehicle + TGF- $\beta 1$ treated (blue curve) dasatinib + TGF- $\beta 1$-treated (ochre curve) were first observed at the 1:00 $\mathrm{h}$ and all later time points

SRC to phosphorylate T $\beta R I I$ [40]. Because this event is upstream of ALK5 activation, SRC is unlikely to be involved in $\mathrm{ALK} 5^{\mathrm{T} 204 \mathrm{D}}$-mediated cell migration consistent with the very similar migration curves of dasatinib and SB431542treated cells.

In the light of our results, the possibility remains that dasatinib's therapeutic effects result to a large extent from inhibition of TGF- $\beta$ signalling rather than signalling by its bona fide target SRC. That dasatinib can indeed compromise undesired effects of TGF- $\beta$ in vivo was suggested by preclinical studies in an in vitro model of a fibrosing disorder in which dasatinib treatment of scleroderma and normal fibroblasts led to decreased production of extracellular matrix proteins [28]. The suppressive effect of dasatinib on TGF- $\beta$ signalling is likely mediated by inhibition of the ALK5 kinase activity and may be exploited therapeutically in more advanced PDAC (when TGF- $\beta 1$ expression and SRC activity are high) to synergistically reduce invasion, metastasis and eventually cancer stem cell formation. Consistent with this, concomitant targeting of EGF-R, TGF- $\beta$ and SRC has been suggested as a novel therapeutic approach in pancreatic cancer [15].

\section{Conclusions}

Understanding how anti-cancer drugs act in vivo is of utmost importance for risk and treatment stratification and for developing targeted combination therapies in advanced PDAC. TGF- $\beta 1$ is a prometastatic ligand in pancreatic cancer which regulates EMT, cell migration/ invasion and cancer stem cell formation. Here, we show that the BCR-ABL/SRC inhibitor dasatinib strongly 
interfered with these tumour-promoting responses, suggesting that the clinical efficiency of dasatinib may be due in part to cross-inhibition of TGF- $\beta$ /ALK5 signalling. Hence, dasatinib may be useful as a dual TGF- $\beta /$ SRC inhibitor in experimental and clinical therapeutics to prevent metastatic spread in late-stage PDAC and other tumours.

\section{Methods}

\section{Reagents}

TGF- $\beta 1$ was obtained from ReliaTech (Wolfenbüttel, Germany). Dasatinib was provided by Bristol-Myers Squibb (UK) and bosutinib (SKI-606) was kindly donated by Pfizer (USA). Stocks of these compounds were prepared in dimethyl sulfoxide (DMSO) which at the concentration used $(0.1 \%)$ had no measurable effect on cellular activities (data not shown).

\section{Cell lines, cell culture and treatment with TGF- $\beta 1$ and inhibitors}

The PDAC cell lines Panc-1 and Colo-357 were maintained in standard culture medium consisting of RPMI 1640 supplemented with $10 \%$ fetal calf serum (FCS), Lglutamine, sodium pyruvate and 50 units $/ \mathrm{ml}$ penicillin and streptomycin. The generation and characterization of individual cell clones from stable retroviral transduction of Panc-1 cells with a kinase-active mutant of ALK5 (T204D mutation) was described in detail in a previous publication [23]. These cells were cultured in the presence of $700 \mu \mathrm{g} / \mathrm{ml}$ geneticin (Life Technologies, Darmstadt, Germany). For stimulation experiments, cells were pretreated with DMSO or inhibitors (Dasatinib, SB431542) for 30-60 min before the addition of TGF- $\beta 1$. The long-term treatment of Panc- 1 cells with TGF- $\beta 1$ was performed in standard culture medium with $2 \%$ FCS according to a previously published protocol [32].

\section{Immunoblot analysis}

Inhibitor-treated cells were lysed in PhosphoSafe buffer (Merck) and the protein concentrations determined with the DC protein assay (Bio-Rad, München, Germany). Equal amounts of cellular proteins were fractionated by SDSPAGE, transferred to PVDF membrane and immunoblotted as described in detail earlier [26]. The antibodies used were: $\beta$-actin (Sigma-Aldrich, \#A1978), N-cadherin (BD Transduction Lab. \#610920), anti-phospho-Smad2(Ser465/467) and anti-phospho-Smad3(Ser423/425), both from Cell Signalling Technology (Frankfurt/Main, Germany), Smad2 (Epitomics, Burlingame, CA, \#1736-1), Smad3 (Abcam, Cambridge, UK, \#ab40854), Snail (Cell Signalling Technology, \#4719), and vimentin (SigmaAldrich, \#V6630). In some experiments, the intensities of bands were quantified by densitometry using $\mathrm{NIH}$ image $\mathrm{J}$.

\section{Quantitative RT-PCR analysis}

The procedure and the conditions for real-time quantitative RT-PCR (qPCR) which was performed on an Icycler with IQ software (Bio-Rad) were published earlier [23]. Primers were generally chosen to span exon-intron boundaries. However because OCT4 is devoid of introns, amplification of its mRNA required the removal of residual genomic DNA from the isolated RNA. Therefore, RNA was prepared with the NucleoSpin ${ }^{\circ}$ RNA isolation kit involving digestion with RNase-free DNase I (MachereyNagel, Düren, Germany). Sequence information for amplification primers is provided in Additional file 1 Table S1 and in Ref. [41]. All values for the genes of interest were normalised to those for $\beta$-actin and TBP, and relative gene expression was calculated by the $2^{-\Delta \Delta} \mathrm{Ct}$ method.

\section{Transient transfection and reporter gene assays}

For reporter gene assays, Panc-1 cells were seeded in 96well plates and cotransfected on the next day (4 h, serumfree) with LipofectAmine 2000 (Life Technologies), either one of the two TGF- $\beta$-responsive promoter-firefly luciferase reporter plasmids 3TPlux and $\mathrm{pCAGA}_{(12)}$-luc (kindly provided by Drs. J. Massagué and S. Dooley, respectively), and the Renilla luciferase encoding vector pRL-TK-luc (Promega, Heidelberg, Germany). Each well received the same total amount of DNA. Following removal of the transfection mixture, cells were allowed to recover overnight in standard growth medium and on the following day were treated with TGF- $\beta 1[5 \mathrm{ng} / \mathrm{ml}]$ and inhibitors or vehicle (added $1 \mathrm{~h}$ prior to the addition of TGF- $\beta 1$ ) for a total of $24 \mathrm{~h}$. Cells were then lysed in Glo lysis buffer (Promega) and luciferase activities determined with the Dual Luciferase Assay System (Promega). In all reporter gene assays, the data for each condition were derived from six parallel wells and were corrected for transfection efficiency with Renilla luciferase activity.

\section{Real-time impedance-based measurement of cell migration}

We applied the xCELLigence RTCA technology (OLS, Bremen, Germany) which represents a non-invasive and label-free approach for continuous (real-time) monitoring of cell migration and invasion on a cell culture level (for review see [42]. Considering that growth factors or their inhibitors may exert maximal effects at different time points after treatment, it is useful to monitor cell behaviour continuously and over a prolonged period of time. The precise determination of peak migratory/invasive activity of a given cell population may aid in deciphering the underlying mechanism of action of receptor kinases and their inhibitors.

Migration experiments were performed using modified 16-well plates (CIM-Plates 16, OLS ). The setup of the experimental device was described in detail earlier [27]. 
To begin an experiment, overnight serum-starved cells (30,000-60,000 per well) were mixed and preincubated with vehicle or dasatinib in $100 \mu \mathrm{l}$ of culture medium containing $1 \%$ FCS. After $30 \mathrm{~min}$, TGF- $\beta 1$ was added to a final concentration of $5 \mathrm{ng} / \mathrm{ml}$ and cells were seeded in the upper chambers. FCS, TGF- $\beta 1$ and inhibitors had been added before to the lower chambers at the same concentrations (chemokinesis). After cell addition, CIMPlates 16 remained at room temperature in the laminar flow hood for $30 \mathrm{~min}$ to allow cells to settle onto the membrane. PBS was added to the empty space surrounding the wells in order to prevent interference from evaporation. Each condition was performed in quadruplicate with a programmed signal detection every $15 \mathrm{~min}$ for a total of 8-24 h depending on the cell type. Data acquisition and analysis was performed with the RTCA software (version 1.2, OLS).

\section{Colony formation assay (CFA)}

The CFAs are commonly used as survival assays to assess the cytotoxic effects of a compound on cell lines and to evaluate the efficacy of anticancer therapeutics. More recently, CFAs became an interesting method in cancer stem cell biology due to their potential to assess the capacity of cells to produce progeny. The assay relies on the assumption that only a cell which is largely undifferentiated can give rise to a countable colony. Consequently, the cell of origin must have features of a stem cell or progenitor cell. The CFA assay was carried out according to published protocols $[33,34]$. Briefly, after treatment of Panc- 1 cells with TGF- $\beta \pm$ dasatinib, cells were detached with Accutase, resuspended in culture medium and centrifuged for $5 \mathrm{~min}$ at $400 \mathrm{~g}$. Subsequently, supernatants were discarded and cell pellets were resuspended in $1 \mathrm{ml}$ of culture medium. Fourhundred cells each were seeded in three wells of a 6-well culture plate for each condition and incubated for14 days. After incubation, medium was aspirated, colonies were washed once in PBS, and fixed with $1 \mathrm{ml} 4.5 \%(w / v)$ paraformaldehyde for $15 \mathrm{~min}$. Colonies were then stained with $0.1 \%$ crystal violet for $1 \mathrm{~h}$ and finally washed twice in $\mathrm{ddH}_{2} \mathrm{O}$ and air-dried overnight. Colonies consisting of at least 50 cells were counted.

\section{Statistical analysis}

Statistical significance was calculated from at least three independent experiments using the unpaired Student's $t$-test. Data were considered significant at $p<0.05$. The levels of significance are as follows: *, $p<0.05$; $*$, $p \leq 0.01 ; * * *, p \leq 0.001$.

\section{Additional file}

Additional file 1: Primers used for qRT-PCR. (DOC $51 \mathrm{~kb}$ )

\section{Abbreviations}

ALK5: activin receptor-like kinase 5; CFA: colony formation assay; EMT: epithelial-to-mesenchymal transition; NSCLC: non-small cell lung carcinoma; PDAC: pancreatic ductal adenocarcinoma; SFK: SRC family kinase; TBP: TATA box binding protein; TGF- $\beta$ : transforming growth factor- $\beta$.

\section{Competing interests}

The authors declare that they have no competing interests.

\section{Authors' contributions}

$\mathrm{TB}, \mathrm{BR}$, and RK carried out the majority of the experimental work, including immunoblot analyses, reporter gene and cell migration assays, and helped in design of the study, interpretation of the data and statistical analysis. HU and FG were the principal designer of the study, performed data analysis and drafted the manuscript. DR, $\mathrm{HB}$ and $\mathrm{HL}$ participated in coordination of the study and critically reviewed and communicated the manuscript. All authors read and approved the final manuscript.

\section{Acknowledgements}

We thank H. Albrecht and S. Grammerstorf for their excellent technical assistance, Dr. J. Massagué (Memorial Sloan Kettering Cancer Center, NY) for generously providing the 3TPlux and ALK5 ${ }^{\text {T204D }}$ plasmids, and Bristol-Myers Squibb for providing dasatinib.

\section{Author details}

${ }^{1}$ First Department of Medicine, UKSH, Campus Lübeck, 23538 Lübeck, Germany. ${ }^{2}$ Department of Radiation Oncology, UKSH, Campus Lübeck, D-23538 Lübeck, Germany. ${ }^{3}$ Department of General, Visceral and Vascular Surgery, Jena University Hospital, D-07747 Jena, Germany.

Received: 17 June 2015 Accepted: 8 November 2015

Published online: 21 November 2015

\section{References}

1. Ito H, Gardner-Thorpe J, Zinner MJ, Ashley SW, Whang EE. Inhibition of tyrosine kinase Src suppresses pancreatic cancer invasiveness. Surgery. 2003;134:221-6.

2. Duxbury MS, Ito H, Zinner MJ, Ashley SW, Whang EE. Inhibition of SRC tyrosine kinase impairs inherent and acquired gemcitabine resistance in human pancreatic adenocarcinoma cells. Clin Cancer Res. 2004;10:2307-18.

3. Ischenko I, Camaj P, Seeliger H. Inhibition of Src tyrosine kinase reverts chemoresistance toward 5-fluorouracil in human pancreatic carcinoma cells: an involvement of epidermal growth factor receptor signalling. Oncogene. 2008;27:7212-22.

4. Shah NP, Tran C, Lee FY, Chen P, Norris D, Sawyers CL. Overriding imatinib resistance with a novel ABL kinase inhibitor. Science. 2004;305:399-401.

5. Chen $\mathrm{R}$, Chen B. The role of dasatinib in the management of chronic myeloid leukemia. Drug Des Devel Ther. 2015;9:773-9.

6. Gnoni A, Marech I, Silvestris N, Vacca A, Lorusso V. Dasatinib: an anti-tumour agent via Src inhibition. Curr Drug Targets. 2011;12:563-78.

7. Trevino JG, Summy JM, Lesslie DP, Parikh NU, Hong DS, Lee FY, et al. Inhibition of SRC expression and activity inhibits tumour progression and metastasis of human pancreatic adenocarcinoma cells in an orthotopic nude mouse model. Am J Pathol. 2006;168:962-72.

8. Nagaraj NS, Smith JJ, Revetta F, Washington MK, Merchant NB. Targeted inhibition of SRC kinase signalling attenuates pancreatic tumourigenesis. Mol Cancer Ther. 2010;9:2322-32.

9. Morton JP, Karim SA, Graham K, Timpson P, Jamieson N, Athineos D, et al. Dasatinib inhibits the development of metastases in a mouse model of pancreatic ductal adenocarcinoma. Gastroenterology. 2010;139:292-303.

10. Chee CE, Krishnamurthi S, Nock CJ, Meropol NJ, Gibbons J, Fu P, et al. Phase II study of dasatinib (BMS-354825) in patients with metastatic adenocarcinoma of the pancreas. Oncologist. 2013;18:1091-2.

11. Montero JC, Seoane S, Ocaña A, Pandiella A. Inhibition of SRC family kinases and receptor tyrosine kinases by dasatinib: possible combinations in solid tumours. Clin Cancer Res. 2011;17:5546-52.

12. Duong HQ, Yi YW, Kang HJ, Bae I, Jang YJ, Kwak SJ, et al. Combination of dasatinib and gemcitabine reduces the ALDH1A1 expression and the proliferation of gemcitabine-resistant pancreatic cancer MIA PaCa-2 cells. Int J Oncol. 2014;44:2132-8. 
13. Hong DS, Choe JH, Naing A, Wheler JJ, Falchook GS, Piha-Paul S, et al. A phase 1 study of gemcitabine combined with dasatinib in patients with advanced solid tumours. Invest New Drugs. 2013;31:918-26.

14. Nagaraj NS, Washington MK, Merchant NB. Combined blockade of Src kinase and epidermal growth factor receptor with gemcitabine overcomes STAT3-mediated resistance of inhibition of pancreatic tumour growth Clin Cancer Res. 2011;17:483-93.

15. Deharvengt S, Marmarelis M, Korc M. Concomitant targeting of EGF receptor, TGF-beta and SRC points to a novel therapeutic approach in pancreatic cancer. PLoS One. 2012;7:e39684

16. Olivieri A, Manzione L. Dasatinib: a new step in molecular target therapy Ann Oncol. 2007;18 Suppl 6:vi42-6.

17. Chang Q, Jorgensen C, Pawson T, Hedley DW. Effects of dasatinib on EphA2 receptor tyrosine kinase activity and downstream signalling in pancreatic cancer. Br J Cancer. 2008;99:1074-82.

18. Li J, Rix U, Fang B, Bai Y, Edwards A, Colinge J, et al. A chemical and phosphoproteomic characterization of dasatinib action in lung cancer. Nat Chem Biol. 2010;6:291-9

19. Gaspar NJ, Li L, Kapoun AM, Medicherla S, Reddy M, Li G, et al. Inhibition of transforming growth factor beta signalling reduces pancreatic adenocarcinoma growth and invasiveness. Mol Pharmacol. 2007:72:152-61.

20. Friess H, Yamanaka Y, Büchler M, Ebert M, Beger HG, Gold LI, et al. Enhanced expression of transforming growth factor beta isoforms in pancreatic cancer correlates with decreased survival. Gastroenterology. 1993:105:1846-56

21. Jones S, Zhang X, Parsons DW, Lin JC, Leary RJ, Angenendt P, et al. Core signalling pathways in human pancreatic cancers revealed by global genomic analyses. Science. 2008;321:1801-6.

22. Derynck R, Zhang YE. Smad-dependent and Smad-independent pathways in TGF- $\beta$ family signalling. Nature. 2003;425:577-84.

23. Schniewind B, Groth S, Sebens Müerköster S, Sipos B, Schäfer H, Kalthoff H et al. Dissecting the role of TGF-beta type I receptor/ALK5 in pancreatic ductal adenocarcinoma: Smad activation is crucial for both the tumour suppressive and prometastatic function. Oncogene. 2007;26:4850-62.

24. Melisi D, Ishiyama S, Sclabas GM, Fleming JB, Xia Q, Tortora G, et al. LY2109761, a novel transforming growth factor beta receptor type I and type II dual inhibitor, as a therapeutic approach to suppressing pancreatic cancer metastasis. Mol Cancer Ther. 2008;7:829-40.

25. Gordian E, Li J, Pevzner Y, Mediavilla-Varela M, Luddy K, Ohaegbulam K, et al. Transforming Growth Factor $\beta$ Signalling Overcomes Dasatinib Resistance in Lung Cancer. PLoS One. 2014;9:e114131.

26. Ungefroren H, Sebens S, Groth S, Gieseler F, Fändrich F. The Src family kinase inhibitors PP2 and PP1 block TGF-beta1-mediated cellular responses by direct and differential inhibition of type I and type II TGF-beta receptors. Curr Cancer Drug Targets. 2011;11:524-35.

27. Bartscht $T$, Lehnert $H$, Gieseler $F$, Ungefroren $H$. The Src family kinase inhibitors PP2 and PP1 effectively block TGF-beta1-induced cell migration and invasion in both established and primary carcinoma cells. Cancer Chemother Pharmacol. 2012;70:221-30.

28. Gordon JK, Spiera RF. Targeting tyrosine kinases: a novel therapeutic strategy for systemic sclerosis. Curr Opin Rheumatol. 2010;22:690-5.

29. Medicherla S, Li L, Ma JY, Kapoun AM, Gaspar NJ, Liu YW, et al. Antitumour activity of TGF-beta inhibitor is dependent on the microenvironment. Anticancer Res. 2007;27:4149-57.

30. Dennler S, Huet S, Gauthier JM. A short amino-acid sequence in $\mathrm{MH1}$ domain is responsible for functional differences between Smad2 and Smad3. Oncogene. 1999;18:1643-8.

31. Engel ME, McDonnell MA, Law BK, Moses HL. Interdependent SMAD and JNK signalling in transforming growth factor-beta-mediated transcription. J Biol Chem. 1999:274:37413-20.

32. Mani SA, Guo W, Liao MJ, Eaton EN, Ayyanan A, Zhou AY, et al. The epithelial-mesenchymal transition generates cells with properties of stem cells. Cell. 2008;133:704-15.

33. Franken NA, Rodermond HM, Stap J, Haveman J, van Bree C. Clonogenic assay of cells in vitro. Nat Protoc. 2006;1:2315-9.

34. Rafehi H, Orlowski C, Georgiadis GT, Ververis K, El-Osta A, Karagiannis TC Clonogenic assay: adherent cells. J Vis Exp. 2011;(49)pii:2573. doi:10.3791/2573

35. Ungefroren $\mathrm{H}$, Sebens $\mathrm{S}$, Giehl K, Helm O, Groth $\mathrm{S}$, Fändrich $\mathrm{F}$, et al. Rac1b negatively regulates TGF- $\beta 1$-induced cell motility in pancreatic ductal epithelial cells by suppressing Smad signalling. Oncotarget. 2014:5:277-90.
36. Ungefroren H, Sebens S, Groth S, Gieseler F, Fändrich F. Differential roles of Src in transforming growth factor- $ß$ regulation of growth arrest, epithelialto-mesenchymal transition and cell migration in pancreatic ductal adenocarcinoma cells. Int J Oncol. 2011:38:797-805.

37. Wieser $\mathrm{R}$, Wrana JL, Massagué J. GS domain mutations that constitutively activate T beta R-I, the downstream signalling component in the TGF-beta receptor complex. EMBO J. 1995;14:2199-208.

38. Boschelli DH, Ye F, Wang YD, Dutia M, Johnson SL, Wu B, et al. Optimization of 4-phenylamino-3-quinolinecarbonitriles as potent inhibitors of Src kinase activity. J Med Chem. 2001;44:3965-77.

39. Calone I, Souchelnytskyi S. Inhibition of TGF $\beta$ signalling and its implications in anticancer treatments. Exp Oncol. 2012;34:9-16.

40. Galliher AJ, Schiemann WP. Src phosphorylates Tyr284 in TGF-beta type I receptor and regulates TGF-beta stimulation of p38 MAPK during breast cancer cell proliferation and invasion. Cancer Res. 2007;67:3752-8.

41. Ungefroren H, Groth S, Hyder A, Thomsen N, Hinz H, Reiling N, et al. The generation of programmable cells of monocytic origin involves partial repression of monocyte/macrophage markers and reactivation of pluripotency genes. Stem Cells Dev. 2010;19:1769-80.

42. Atienza JM, Yu N, Kirstein SL, Xi B, Wang X, Xu X, et al. Dynamic and label-free cell-based assays using the real-time cell electronic sensing system. Assay Drug Dev Technol. 2006;4:597-607.

\section{Submit your next manuscript to BioMed Central and take full advantage of:}

- Convenient online submission

- Thorough peer review

- No space constraints or color figure charges

- Immediate publication on acceptance

- Inclusion in PubMed, CAS, Scopus and Google Scholar

- Research which is freely available for redistribution 